of comorbidities. SSc related risk factors were SSc subtype, autoantibodies, disease duration, SSc associated organ manifestations including interstitial lung disease (ILD), pulmonary arterial hypertension (PAH), cardiac, gastrointestinal (GI), and musculoskeletal involvement; digital ulcers (DU), CRP at last visit, renal disease (scleroderma renal crisis and SSc associated renal insufficiency), modified Rodnan skin score (mRSS) and immunosuppressive treatment. Descriptive statistics and logistic regression models were applied.

Results: In total, 178 European SSc patients with COVID-19 were registered with a median observation time of 5.5 weeks (Table 1). 95 patients $(53 \%)$ could recall SAR-Cov-2 contact, while 47 (26\%) had no contact. 156 (88\%) were symptomatic at COVID-19 onset with fever, cough, malaise and dyspnea being most prevalent. Over the disease course, $63(36 \%)$ developed pneumonia. In total, $67 / 176$ (38\%) were hospitalized which were in $84 \%$ due to COVID-19. 41/170 (24\%) had a severe outcome including $21(12 \%)$ deaths. $128(72 \%)$ recovered completely, while $14(8 \%)$ complained of sequela, with $7(50 \%)$ stating respiratory complications. Age, non-SSc comorbidities, presence of ILD, PAH and SSc associated renal or cardiac disease were numerically associated with hospitalization and severe outcome (Table 1). Univariable logistic analyses for hospitalization and severe outcome are shown in Figure 1. In multivariable logistic regression, age $(\mathrm{OR} 1.03,95 \% \mathrm{Cl}$ 1.01-1.07, $p=0.019$ ), presence of non-SSc comorbidities (OR 2.52, 95\% Cl $1.16-5.47, p=0.019$ ) and SSc-related renal disease (predicting success perfectly) were associated with hospitalization and for severe outcome age (OR $1.05,95 \% \mathrm{Cl} 1.01-1.08)$.

Conclusion: SSc patients at older age, with non-SSc comorbidities, SSc related renal disease or ILD are at risk of a more severe outcome and should follow precautions to avoid COVID-19 infections and need careful monitoring in case of COVID-19.

Table 1. SSc disease characteristics of COVID-19 patients

\begin{tabular}{lccc}
\hline & $\begin{array}{c}\text { All } \\
(\mathrm{n}=172)\end{array}$ & $\begin{array}{c}\text { Hospitalized } \\
(\mathrm{n}=67)\end{array}$ & $\begin{array}{c}\text { Severe outcome } \\
(\mathrm{n}=41)\end{array}$ \\
\hline Age at COVID-19, yrs (SD) & $57(14.0)$ & $63(13.8)$ & $65(12.2)$ \\
Male sex, $\mathrm{n}(\%)$ & $38(21)$ & $18(27)$ & $12(29)$ \\
$\geq 1$ comorbidity, $\mathrm{n}(\%)$ & $63 / 176(36)$ & $37(55)$ & $30(58)$ \\
SSc disease duration at COVID, yrs (SD) & $11.5(8.8)$ & $13.3(9.7)$ & $12.7(10.2)$ \\
Diffuse cutaneous SSc, $\mathrm{n}(\%)$ & $74(42)$ & $29(43)$ & $19(46)$ \\
mRSS, median (IQR) & $5(8)$ & $5(9)$ & $5(7)$ \\
ILD, $\mathrm{n}(\%)$ & $90 / 175(51)$ & $36 / 65(55)$ & $26 / 40(65)$ \\
PAH, $\mathrm{n}(\%)$ & $21 / 175(12)$ & $11 / 65(17)$ & $8 / 40(20)$ \\
Gl disease, $\mathrm{n}(\%)$ & $112 / 176(64)$ & $45(67)$ & $30(73)$ \\
Cardiac disease, $\mathrm{n}(\%)$ & $37 / 166(22)$ & $19 / 59(32)$ & $16 / 36(44)$ \\
Musculoskeletal disease, $\mathrm{n}(\%)$ & $40 / 175(23)$ & $15 / 65(23)$ & $6 / 40(15)$ \\
Renal disease, $\mathrm{n}(\%)$ & $8 / 175(5)$ & $7 / 65(11)$ & $5 / 40(13)$ \\
Ever DU, $\mathrm{n}(\%)$ & $69 / 175(39)$ & $27 / 65(42)$ & $14 / 40(35)$ \\
CRP, nglml (SD) & $35 / 177(20)$ & $14(21)$ & $9(22)$ \\
Immunosuppressive treatment, $\mathrm{n}(\%)$ & $104 / 177(59)$ & $41 / 66(62)$ & $26(63)$ \\
\hline
\end{tabular}
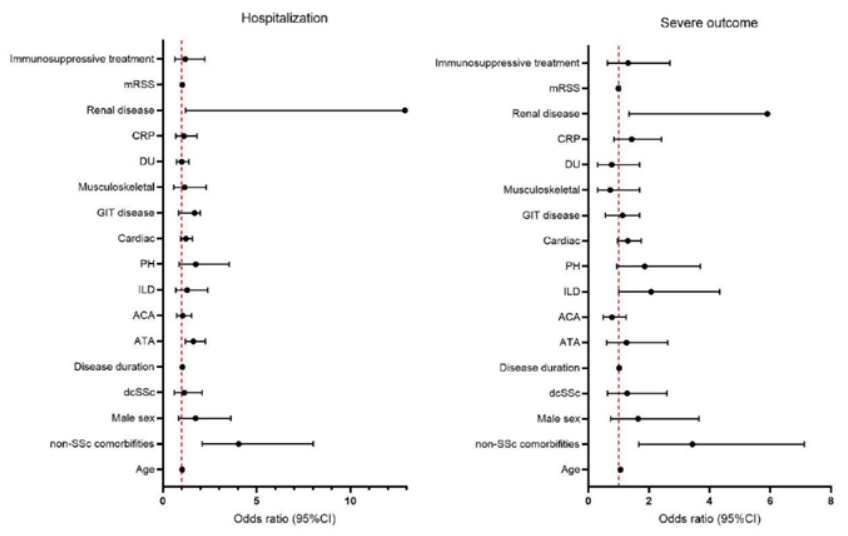

Figure 1. Univariable logistic analyses for hospitalization and severe outcome

Disclosure of Interests: Anna-Maria Hoffmann-Vold Speakers bureau: Actelion, Boehringer Ingelheim, Roche, Merck Sharp \& Dohme, ARXX, Lilly and Medscape, Consultant of: Actelion, Boehringer Ingelheim, Bayer, ARXX, and Medscape
, Grant/research support from: Boehringer Ingelheim, Cathrine Brunborg: None declared, Francesca Tirelli: None declared, Patricia Carreira: None declared, Nicoletta Del Papa: None declared, Arsene Mekinian: None declared, MadeIon Vonk: None declared, Alessandro Giollo: None declared, Giacomo De Luca: None declared, Maria De Santis: None declared, Corrado Campochiaro: None declared, Carina Mihai: None declared, Paolo Airò Speakers bureau: Bristol Myers Squibb, Bohringer Ingelheim, Consultant of: Bristol Myers Squibb, Bohringer Ingelheim, non-financial support from CSL Behring, SOBI, Janssen, Roche, Sanofi, Pfizer, Maria Grazia Lazzaroni: None declared, Elisabetta Zanatta: None declared, Rosario Foti: None declared, Yannick Allanore: None declared, Daniel Furst: None declared, Marco Matucci-Cerinic: None declared, Armando Gabrielli: None declared, Oliver Distler Speakers bureau: Actelion, Kymera Therapeutics, Mitsubishi Tanabe Pharma, Abbvie, Acceleron, Alexion, Amgen, AnaMar, Arxx Therapeutics, Baecon, Discovery, Blade Therapeutics Corbus Pharmaceuticals, Drug Development International, Ltd, CSL Behring, Galapagos NV, Glenmark Pharmaceuticals, GSK, Horizon (Curzion) Pharmaceuticals, Inventiva, iQvia, Kymera Therapeutics, Lilly, Novartis, Pfizer, Topadur and UCB, Consultant of: Actelion, Kymera Therapeutics, Mitsubishi Tanabe Pharma, Abbvie, Acceleron, Alexion, Amgen, AnaMar, Arxx Therapeutics, Baecon, Discovery, Blade Therapeutics, Corbus Pharmaceuticals, Drug Development International, Ltd, CSL Behring, Galapagos NV, Glenmark Pharmaceuticals, GSK, Horizon (Curzion) Pharmaceuticals, Inventiva, iQvia, Kymera Therapeutics, Lilly, Novartis, Pfizer, Topadur and UCB, Grant/research support from: Boehringer Ingelheim.

DOI: 10.1136/annrheumdis-2021-eular.3267

\section{POS0055 SARS-COV-2 OUTBREAK IN AUTOIMMUNE DISEASES: THE EURO-COVIMID STUDY}

D. Saadoun ${ }^{1}$, M. Vieira ${ }^{1}$, M. Vautier ${ }^{1}$, X. Baraliakos ${ }^{2}$, I. Andreica ${ }^{2}$, J. A.

P. Da Silva ${ }^{3}$, M. Sousa ${ }^{3}$, M. Luis $^{3}$, N. Khmelinskii ${ }^{4}$, J. M. Alvaro-Gracia ${ }^{5}$, I. Castrejon ${ }^{5}$, J. C. Nieto González ${ }^{5}$, C. A. Scirè ${ }^{6}$, E. Silvagni ${ }^{6}$, A. Bortoluzzi ${ }^{6}$, H. Penn ${ }^{7}$, S. Hamdulay ${ }^{7}$, P. Machado ${ }^{7}$, B. Fautrel ${ }^{8,9}$, P. Cacoub ${ }^{1}$, M. RescheRigon $^{10}$, L. Gossec ${ }^{8,9} .{ }^{1}$ University Hospitals Pitié Salpêtrière - Charles Foix, Département de Médecine Interne et Immunologie Clinique, Centre National de Références Maladies Autoimmunes systémiques rares, Centre National de Références Maladies Autoinflammatoires et Amylose Inflammatoire, Paris, France; ${ }^{2}$ Ruhr-Universität Bochum, Rheumazentrum Ruhrgebiet, Bochum, Germany; ${ }^{3}$ Centro Hospitalar e Universitário de Coimbra, Rheumatology Department, Coimbra, Portugal; ${ }^{4}$ Hospital de Santa Maria, Rheumatology Department, Lisboa, Portugal; ${ }^{5}$ Gregorio Marañón Hospital, Rheumatology, Madrid, Spain; ${ }^{6}$ University of Ferrara, Department of Medical Sciences, Ferrara, Italy; ${ }^{7}$ Northwick Park Hospital, Department of Rheumatology, London, United Kingdom; ${ }^{8}$ University Hospitals Pitié Salpêtrière - Charles Foix, Rheumatology Department, Paris, France; ${ }^{9}$ Pierre Louis Institute of Epidemiology and Public Health, Inserm UMR 1136, PEPITES team, Paris, France; ${ }^{10}$ Hospital Saint-Louis, URC Saint-Louis, Paris, France

Background: Coronavirus disease 2019 (COVID-19), has raised several questions in patients with immune-mediated inflammatory diseases (IMID). Whether the seroprevalence and factors associated with symptomatic COVID-19 are similar in IMID patients and in the general population is still unknown.

Objectives: To assess the serological and clinical prevalence of COVID-19 in European IMID patients, along with the factors associated with its risk and the impacts the pandemic had on the IMID management.

Methods: Prospective multicentre cross-sectional study among patients with five IMID (i.e. systemic lupus erythematous, Sjögren's syndrome, rheumatoid arthritis, axial spondylarthritis or giant cell arteritis) from six tertiary-referral centers from France, Germany, Italy, Portugal, Spain and United Kingdom. Demographics, comorbidities, IMID, treatments, flares and COVID-19 details were collected. Severe acute respiratory syndrome coronavirus 2 (SARS-CoV-2) serological tests were systematically performed.

Results: Between June 7 and December 8, 2020, 3028 patients were included (median age 58 years, $73.9 \%$ females). SARS-CoV-2 antibodies were detected in 166 (5.5\%) patients. Symptomatic COVID-19 was seen in 122 patients (prevalence: $4.0 \%, 95 \% \mathrm{Cl} 3.4-4.8 \%) ; 23(24.2 \%)$ of them were hospitalized and four (3.2\%) died. In multivariate logistic regression analysis, symptomatic COVID-19 was more likely to be observed in patients with higher levels of $\mathrm{C}$-reactive protein (OR: $1.18 ; 95 \% \mathrm{Cl} 1.05-1.33 ; \mathrm{p}=0.006$ ), and increased with the number of IMID flares (OR: 1.27; $95 \% \mathrm{Cl} 1.02-1.58 ; p=$ $0.03)$. Conversely, it was less likely to occur in patients treated with biological therapy (OR: $0.51 ; 95 \% \mathrm{Cl} 0.32-0.82 ; \mathrm{p}=0.006)$. During the pandemic, at least one self-reported disease flare was seen in $654(21.6 \%)$ patients. Also, 519 $(20.6 \%)$ patients experienced changes in their treatment, with 125 of these (24.1\%) being due to COVID-19. 
Conclusion: The SARS-CoV-2 prevalence in IMID patients over the study period seems to be similar to that of the general population ${ }^{1}$. The IMID inflammatory status seems to be independently associated with the development of COVID-19.

REFERENCES:

[1] Pollán $M$, Pérez-Gómez $B$, Pastor-Barriuso $R$, Oteo J, Hernán MA, Pérez-Olmeda M, et al. Prevalence of SARS-CoV-2 in Spain (ENE-COVID): a nationwide, population-based seroepidemiological study. Lancet Lond Engl. 2020 Aug 22;396(10250):535-44.

Disclosure of Interests: None declared.

DOI: 10.1136/annrheumdis-2021-eular.3368

\section{POS0056 ANXIETY AND CONCERNS RELATED TO THE WORK SITUATION DURING THE COVID-19 PANDEMIC IN $>5,000$ PATIENTS WITH INFLAMMATORY RHEUMATIC DISEASE FOLLOWED IN THE DANISH DANBIO REGISTRY, RESULTS FROM A NATIONWIDE QUESTIONNAIRE}

B. Glintborg ${ }^{1}$, D. V. Jensen ${ }^{2}$, S. Engel ${ }^{1}$, L. Terslev ${ }^{1}$, M. Pfeiffer Jensen ${ }^{1}$, O. Hendricks ${ }^{3}$, M. Østergaard ${ }^{1}$, S. H. Rasmussen ${ }^{1}$, T. Adelsten ${ }^{4}$, A. Colic ${ }^{4}$, K. Danebod ${ }^{1}$, M. Kildemand ${ }^{5}$, A. G. Loft ${ }^{6}$, H. L. Munk ${ }^{7}$, J. K. Pedersen ${ }^{8}$, R. Østgård ${ }^{9}$, C. M. Sørensen ${ }^{10}$, N. Steen Krogh ${ }^{11}$, J. Nørgaard Agerbo ${ }^{12}$, C. Ziegler ${ }^{12}$, M. L. Hetland ${ }^{1} .{ }^{1}$ Centre of Head and Orthopedics, Rigshospitalet, DANBIO and Copenhagen Center for Arthritis Research (COPECARE), Center for Rheumatology and Spine Diseases, Glostrup, Denmark; ${ }^{2}$ Gentofte and Herlev Hospital, Department of rheumatology, Center for Rheumatology and Spine Diseases, Gentofte, Denmark; ${ }^{3}$ University Hospital of Southern Denmark, Sønderborg, Danish Hospital for Rheumatic Diseases, Sønderborg, Denmark; ${ }^{4}$ Zealand University Hospital, Department of Rheumatology, Køge, Denmark; ${ }^{5}$ Odense University Hospital, Department of Rheumatology, Odense, Denmark; ${ }^{6}$ Aarhus University Hospital, Department of Rheumatology, Aarhus, Denmark; ${ }^{7}$ Odense University Hospital, Department of Rheumatology, Odense, Denmark; ${ }^{8}$ Odense University Hospital and Svendborg Hospital, Department of Rheumatology, Odense and Svendborg, Denmark; ${ }^{9}$ Silkeborg Regional Hospital, Diagnostic Center, Silkeborg, Denmark; ${ }^{10}$ Horsens Regional Hospital, Department of Medicine, Horsens, Denmark; ${ }^{11}$ ZiteLab Aps, Copenhagen, Denmark; ${ }^{12}$ Gigtforeningen/Danish Rheumatism Association, Copenhagen, Denmark

Background: During the COVID-19 pandemic, widespread changes in how we work have been observed. Working from home is not an option for everyone. At work it may be difficult to keep social distance, which may lead to fear and anxiety of being infected with SARS-CoV-19 or of spreading the virus.

Objectives: To explore frequency of anxiety and concerns related to work in patients with inflammatory rheumatic diseases(IRD) during the COVID-19 pandemic and to identify patient and disease characteristics associated with increased anxiety.

Methods: Patients in routine care followed in the nationwide Danish DANBIO registry were invited to answer an on-line questionnaire regarding current rheumatic disease activity, behavior and anxiety including current work-status and -concerns. Responses were linked to patient data previously recorded in DANBIO. Clinical factors associated with work-related concerns (completely/mostly agree versus neither/nor, completely/mostly disagree) were explored with multivariable logistic regression

Results: Among 14,758 respondents (38\% of eligible patients), 5,950 patients $(40 \%)$ were currently working $(60 \%$ full time/31\% part time/ $9 \%$ self-employed) $(61 \%$ female, $53 \%$ rheumatoid arthritis $/ 19 \%$ psoriatic arthritis/20\% axial spondyloarthritis/9\% other). Although $68 \%$ reported that the workplace helped to make necessary interventions, work-related concerns and anxiety were frequent. Thus, $22 \%$ found it difficult (completely/mostly agree) to keep physical distance at work and $20 \%$ were worried about going to work (Figure 1).

Factors associated with concerns about going to work were female gender, longer education, other chronic conditions, biological therapy, and higher (=poorer) EQ-5D, whereas diagnosis was without significance. Similar patterns were found for other work-related concerns (not shown).

Conclusion: In this cohort of $>5,000$ patients with inflammatory rheumatic diseases followed in a nationwide registry, during the COVID-19 pandemic anxiety and concerns related to the work situation were frequent, especially in women and patients treated with biologicals, with other chronic diseases and with poor quality of life.

\section{REFERENCES:}

[1] Glintborg et al, 2021, https://rmdopen.bmj.com/content/rmdopen/7/1/ e001505.full.pdf

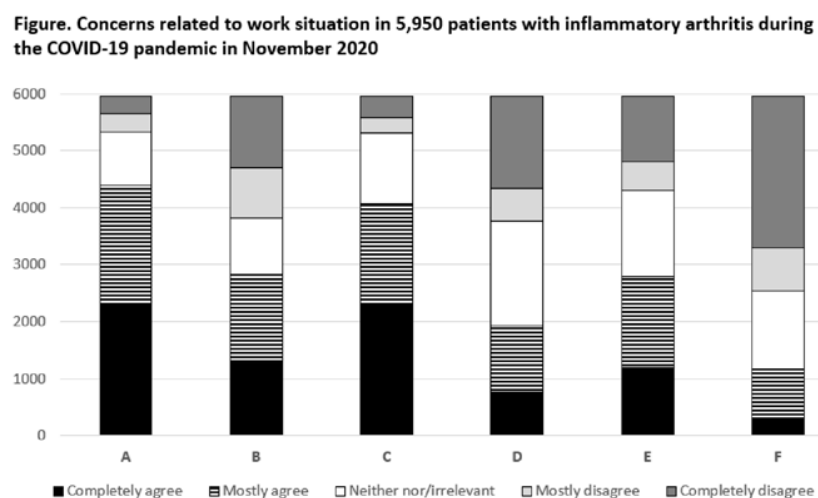

Questions: A: It is important for me to keep physical distance at my job, B: It is difficult for me to keep physical distance at my job, C: My work-place helped to make necessary interventions for me to safely tend my job, D: I fear that my arthritis condition increases my risk of COVID-19 infection at work more than others my age, E: Due to my arthritis condition I should take more precautions at work to avoid infection compared to others my age, F: I am worried to go to work

Table 1. Factors associated with being worried (agree versus disagree) to go to work (Figure 1, panel F). Multivariable logistic regression analyses

\begin{tabular}{llll}
\hline & & Odds ratio $(95 \% \mathrm{Cl})$ & $\mathrm{p}$ \\
\hline Gender & female & 1 & \\
& male & $0.45(0.38 ; 0.54)$ & $<0.001$ \\
Age, years & 40 & 1 & \\
& $40-60$ & $1.12(0.87 ; 1.44)$ & 0.4 \\
Education & $>60$ & $0.89(0.67 ; 1.20)$ & 0.5 \\
& Long & 1 & \\
Living alone, yes & No/short & $0.80(0.69 ; 0.93)$ & 0.005 \\
Other chronic condition, yes & & $0.97(0.79 ; 1.20)$ & 0.8 \\
Biological therapy & & $1.37(1.17 ; 1.59)$ & $<0.001$ \\
Diagnosis & Rheumatoid arthritis & $1.36(1.17 ; 1.58)$ & $<0.001$ \\
& Psoriatic arthritis & $1.21(0.99 ; 1.48)$ & 0.06 \\
& Axial spondyloarthritis & $1.03(0.84 ; 1.28)$ & 0.8 \\
PASS, yes ${ }^{*}$ & Other & $1.17(0.89 ; 1.54)$ & 0.3 \\
Smoking & & $1.03(0.85 ; 1.25)$ & 0.7 \\
& Current & 1 & \\
EQ5D** & Previous & $1.17(0.94 ; 1.47)$ & 0.2 \\
& Never & $1.10(0.90 ; 1.35)$ & 0.4 \\
*atient acceptable & $0.03(0.02 ; 0.06)$ & $<0.001$ \\
\hline
\end{tabular}

*patient acceptable symptom state, ${ }^{* \star}$ European Quality of Life, 5 dimensions

Disclosure of Interests: Bente Glintborg Grant/research support from: AbbVie BMS, Pfizer, Dorte Vendelbo Jensen: None declared, Sara Engel: None declared, Lene Terslev Speakers bureau: AbbVie, Janssen, Roche, Novartis, Pfizer, MSD, BMS and GE, Mogens Pfeiffer Jensen: None declared, Oliver Hendricks: None declared, Mikkel Østergaard Speakers bureau: Abbvie, BMS, Boehringer-Ingelheim, Celgene, Eli-Lilly, Hospira, Janssen, Merck, Novartis, Novo, Orion, Pfizer Regeneron, Roche, Sandoz, Sanofi and UCB., Grant/research support from: Abbvie, BMS, Celgene, Merck, Novartis, Simon Horskjær Rasmussen: None declared, Thomas Adelsten: None declared, Ada Colic: None declared, Kamilla Danebod: None declared, Malene Kildemand: None declared, Anne Gitte Loft Speakers bureau: AbbVie, Eli-Lilly, Janssen, MSD, Novartis, Pfizer, and UCB Heidi Lausten Munk: None declared, Jens Kristian Pedersen: None declared, René Østgård Speakers bureau: Abbvie, BMS, Boehringer-Ingelheim, Eli-Lilly, Janssen, Merck, Novartis, Pfizer, Roche, Sanofi and UCB., Grant/research support from: Abbvie, Christian Møller Sørensen: None declared, Niels Steen Krogh None declared, Jette Nørgaard Agerbo: None declared, Connie Ziegler: None declared, Merete L. Hetland Grant/research support from: AbbVie, Biogen, BMS Celtrion, Eli Lilly Denmark A/S, Janssen Biologics B.V, Lundbeck Fonden, MSD, Pfizer, Roche, Samsung Biopis, Sandoz. MLH chairs the steering committee of the Danish Rheumatology Quality Registry (DANBIO), which receives public funding from the hospital owners and funding from pharmaceutical companies. $\mathrm{MLH}$ co-chairs the EuroSpA research collaboration, which generates real-world evidence of treatment of psoriatic arthritis and axial spondylorthritis based on secondary data and is partly funded by Novartis.

DOI: 10.1136/annrheumdis-2021-eular.721 